\title{
Official quality control of plant protection products in Poland in 2011-2015
}

\author{
Urzędowa kontrola jakości środków ochrony roślin w Polsce \\ w latach 2011-2015
}

\author{
Marek Miszczyk*, Marlena Płonka, Dorota Kronenbach-Dylong
}

\begin{abstract}
Summary
European Union law regulation imposes on Member States the obligation to conduct independent from manufacturers, official quality control of plant protection products that are authorized for application. In Poland in 2011-2015 such a control was carried out in cooperation with the Ministry of Agriculture and Rural Development, State Inspectorate of Plant Health and Seed and the Institute of Plant Protection - National Research Institute Sośnicowice Branch. The official control is designed to check whether the plant protection products placed on the market in Poland are of sufficient quality and if they meet the technical requirements established for them in the process of their registration. A total of 1,596 samples of plant protection products were examined and herbicides accounted for $53.9 \%$, fungicides for $27.2 \%$ and insecticides for $11.8 \%$. Illegal origin and falsification of plant protection products are the main causes of the negative phenomena results in the pesticide market in Poland.
\end{abstract}

Key words: official control; plant protection products; Poland

\section{Streszczenie}

Prawo unijne nakłada na kraje członkowskie Unii Europejskiej obowiązek przeprowadzania niezależnej od producentów, urzędowej kontroli jakości dopuszczonych do stosowania środków ochrony roślin. W Polsce w latach 2011-2015 kontrola taka przeprowadzana była przy współpracy Ministerstwa Rolnictwa i Rozwoju Wsi, Państwowej Inspekcji Ochrony Roślin i Nasiennictwa oraz Instytutu Ochrony Roślin - Państwowego Instytutu Badawczego Oddział Sośnicowice. Kontrola urzędowa ma na celu sprawdzenie, czy środki ochrony roślin znajdujące się w obrocie handlowym w Polsce są odpowiedniej jakości, czyli czy spełniają wymagania techniczne ustalone dla nich w procesie ich rejestracji. W ramach kontroli jakości przebadano ogółem 1596 próbek środków ochrony roślin, w tym $53,9 \%$ stanowiły herbicydy, 27,2\% fungicydy, a 11,8\% insektycydy. Nielegalne pochodzenie oraz fałszerstwa środków ochrony roślin, to główne przyczyny negatywnych zjawisk na rynku pestycydowym w Polsce.

Słowa kluczowe: kontrola urzędowa; jakość środków ochrony roślin; Polska

Instytut Ochrony Roślin - Państwowy Instytut Badawczy

Oddział Sośnicowice

Gliwicka 29, 44-153 Sośnicowice

*corresponding author: m.miszczyk@ior.gliwice.pl 


\section{Wstęp / Introduction}

Kraje członkowskie Unii Europejskiej (UE) na mocy artykułu 68 Rozporządzenia Parlamentu Europejskiego i Rady z dnia 21.10.2009 r. (Rozporządzenie 1107/2009) zobowiązane są do przeprowadzania urzędowych kontroli jakości środków ochrony roślin (ś.o.r.) dopuszczonych do obrotu. W Polsce realizacja tego zadania jest statutowym obowiązkiem Państwowej Inspekcji Ochrony Roślin i Nasiennictwa (PIORiN). W latach 2011-2015, w badaniach kontrolnych brał udział Instytut Ochrony Roślin Państwowy Instytut Badawczy (IOR - PIB) w ramach realizacji Programu Wieloletniego na podstawie umowy pomiędzy IOR - PIB a Ministerstwem Rolnictwa i Rozwoju Wsi (MRiRW). Zadanie realizowano w Laboratorium Badania Jakości Środków Ochrony Roślin (LBJŚOR) IOR - PIB Oddział Sośnicowice. Wykonywane badania miały na celu stwierdzenie, czy ś.o.r. będące w obrocie handlowym i stosowaniu w Polsce spełniają wymagania specyfikacji technicznych ustalonych w procesie ich rejestracji. Działania te miały zapobiegać użyciu ś.o.r. złej jakości, których zastosowanie może wywołać niewłaściwy efekt dla roślin uprawnych, ludzi, zwierząt i środowiska.

\section{Materiały i metody / Materials and methods}

Przedmiotem badań były próbki chemicznych ś.o.r. pobierane $\mathrm{w}$ oryginalnych, jednostkowych opakowaniach. Każdego roku, próbki środków do badań pobierane były przez inspektorów PIORiN zgodnie z ustalonym przez Główny Inspektorat Ochrony Roślin i Nasiennictwa (GIORiN) planem. Do końca 2011 roku funkcjonowały trzy rodzaje urzędowej kontroli ś.o.r. Pierwszy rodzaj, to kontrola planowana, polegająca na sprawdzeniu jakości ś.o.r. zawierających wytypowane substancje czynne. Drugi rodzaj, to kontrola wyrywkowa, która polegała na sprawdzeniu jakości ś.o.r. pobranych z sieci handlowych w sposób losowy. Pobierano próbki należące do wszystkich grup środków produkcji krajowej i importowanych. W ramach trzeciego rodzaju kontroli wykonywano analizy mające na celu rozpatrzenie skarg i reklamacji, spraw $\mathrm{w}$ toczących się postępowaniach administracyjnych, fałszerstw ś.o.r., dochodzeń policji i prokuratury, itp. Ten rodzaj kontroli, to kontrola interwencyjna. W roku 2012 program poboru próbek uległ zmianom. W ramach realizacji Programu Wieloletniego na lata 2011-2015 wykonywano Zadanie 1.7. „Opracowanie podstaw statystycznych działań kontrolnych Państwowej Inspekcji Ochrony Roślin i Nasiennictwa”, którego jednym z rezultatów było opracowanie nowych wytycznych pobierania próbek w celu urzędowej kontroli jakości przeprowadzanej przez PIORiN. Zasadnicza zmiana w stosunku do poprzedniego systemu polegała na ukierunkowaniu działań na wykrywanie nieprawidłowości, czyli odstępstw od wymagań jakościowych. Jako ogólną zasadę nowego systemu przyjęto, że kontrola powinna zapewniać monitoring we wszystkich kontrolowanych obszarach przy równoczesnym ukierunkowaniu na obszary szczególnie zagrożone, czyli stanowić system monitoringowo-prewencyjny lub inaczej monitoring stymulujący. Obszary szczególnie zagrożone to te, w których stwierdzono najwięcej nieprawidłowości. Celem zidentyfikowania tych obszarów, na etapie ustalania programu kontroli na dany rok, dokonywano analizy statystycznej danych z poprzednich dwóch lat, co umożliwiło coroczną aktualizację systemu. Nowy program kontroli urzędowej zredukował liczbę rodzajów kontroli do dwóch. Od 2012 roku funkcjonowała kontrola podstawowa (celowa) (K), która polegała na sprawdzeniu jakości ś.o.r. pobranych $\mathrm{z}$ sieci handlowych w sposób celowy, zgodnie z wytycznymi GIORiN, natomiast drugi rodzaj kontroli stanowiła kontrola interwencyjna (KI), której funkcja nie uległa zmianie w stosunku do lat wcześniejszych. W latach 2011-2015 ustalany na każdy rok plan kontroli zakładał analizę 300-310 próbek ś.o.r., w tym 260 w ramach kontroli podstawowej (planowanej i wyrywkowej w 2011 roku) oraz 50 próbek interwencyjnych. Od 2013 roku W obrębie kontroli podstawowej rozpoczęto realizować kontrolę jakości środków z dużych opakowań (zawartość powyżej 51 lub $5 \mathrm{~kg}$ ). Plan kontroli zakładał pobór 20-30 próbek z tego rodzaju opakowań. Każdego roku Główny Inspektor Ochrony Roślin i Nasiennictwa wskazywał województwa, na terenie których dokonywany będzie pobór próbek z dużych opakowań.

Badania dostarczonych do LBJŚOR próbek ś.o.r. wykonywane były w oparciu o obowiązujące normy, zalecenia, przepisy i wytyczne międzynarodowe (CIPAC Collaborative International Pesticides Analytical Council), literaturę krajową i zagraniczną oraz bardzo często w oparciu o opracowane metody własne.

W zakresie oznaczeń substancji czynnych i składu ś.o.r. stosowano:

- metody miareczkowe (różne warianty),

- techniki chromatografii gazowej (chromatografia gazowa - GC - Gas Chromatography, chromatografia gazowa połączona ze spektrometrem mas GC-MS - Gas Chromatography-Mass Spectrometry, chromatografia gazowa $\mathrm{z}$ techniką analizy fazy nadpowierzchniowej połączona ze spektrometrem mas - HS-GC/MS - Head Space-Gas Chromatography/Mass Spectrometry),

- techniki chromatografii cieczowej (wysokosprawna chromatografia cieczowa - HPLC - High-Performance Liquid Chromatography, chromatografia cieczowa połączona $\mathrm{z}$ tandemowym spektrometrem mas - LC-MS/MS - Liquid Chromatography-tandem Mass Spectrometry),

- spektrometrię W zakresie bliskiej podczerwieni (NIR - Near Infrared spectrometry).

W zakresie parametrów fizykochemicznych form użytkowych ś.o.r. wykonywano oznaczenia:

- trwałości zawiesiny (MT 184 CIPAC K 2003),

- trwałości emulsji (MT 36.3 CIPAC K 2003),

- czasu zwilżania (MT 53 CIPAC F 1995),

- pozostałości na sicie mokrym (MT 185 CIPAC K 2003),

- pH (MT 75.3 CIPAC J 2000),

- gęstości (MT 3 CIPAC F 1995),

- stopnia rozpuszczalności i stabilności roztworu (MT 179 CIPAC H 1998). 
Oznaczenia zawartości wody przeprowadzano, w zależności od specyfiki badanej próbki, w oparciu o metodę Deana-Starka (MT 30.2 CIPAC F 1995) lub Karla Fishera (MT 30.5 CIPAC J 2000).

Do badań porównawczych wykorzystywano preparaty dostarczone bezpośrednio przez producenta wraz z certyfikatem poświadczającym ich właściwą jakość oraz oryginalne pochodzenie (środki referencyjne). Środki referencyjne przekazywano do LBJŚOR za pośrednictwem GIORiN. Celem analiz porównawczych była weryfikacja oryginalnego pochodzenia badanego środka, a w przypad$\mathrm{ku}$ produktów objętych handlem równoległym, potwierdzenie identyczności w stosunku do środka wskazanego w pozwoleniu na handel równoległy (środek referencyjny). Podstawę analiz porównawczych stanowiły dane uzyskane dla środka badanego oraz środka referencyjnego przy pomocy różnych technik chromatograficznych (HPLC, GC, GC-MS, HS-GC-MS). Porównanie tych danych pozwoliło na stwierdzenie, czy skład badanego środka jest tożsamy ze składem środka oryginalnego (referencyjnego). W uzasadnionych przypadkach dodatkowo wykonywano pogłębioną analizę składu badanych środków obejmującą oznaczenie wybranych zanieczyszczeń oraz składników formulacji.

\section{Wyniki i dyskusja / Results and discussion}

W ramach kontroli urzędowej przeprowadzonej w latach 2011-2015 przebadano ogółem 1596 próbek ś.o.r., w tym 1332 próbki pobrane w ramach kontroli podstawowej, a $264 \mathrm{w}$ ramach kontroli interwencyjnej. Wśród próbek objętych kontrolą podstawową, odsetek próbek wykazujących poważne nieprawidłowości stanowiące podstawę do podjęcia decyzji o wycofaniu towaru z obrotu, stanowił 3,7\%. Natomiast dla próbek interwencyjnych odsetek nieprawidłowości wyniósł aż 62,5\% całkowitej liczby próbek objętych tym rodzajem kontroli. W sprawach, które wykraczały poza kompetencje laboratorium kontrolnego, opinia do atestu nie zawierała orzeczenia o możliwości wprowadzenia do obrotu handlowego i stosowania. Szczegółowe wyniki kontroli urzędowej przeprowadzonej w latach 2011-2015 zamieszczono w tabeli 1 . Wyniki przeprowadzonych badań wskazują, że obszarem najbardziej narażonym na występowanie nieprawidłowości są ś.o.r. objęte handlem równoległym. W latach 2011-2015 w ramach kontroli podstawowej badano 250 próbek środków $\mathrm{Z}$ handlu równoległego. Odsetek nieprawidłowości w tej grupie środków wyniósł $12 \%$, co daje $2,3 \%$ w stosunku do całkowitej liczby próbek objętych kontrolą podstawową. $\mathrm{W}$ grupie próbek środków $\mathrm{z}$ handlu równoległego pochodzących $\mathrm{Z}$ poboru interwencyjnego odsetek nieprawidłowości wyniósł 78,8\%, czyli $29,6 \% \mathrm{w}$ stosunku do 264 próbek badanych w ramach kontroli interwencyjnej. Nieprawidłowości stwierdzone w grupie próbek środków, które uzyskały zezwolenie na wprowadzenie do obrotu w normalnym trybie, wyniosły w kontroli podstawowej $1,6 \%$. Podstawową przyczyną dyskwalifikacji środków objętych handlem równoległym był brak obligatoryjnej identyczności w stosunku do środka referencyjnego, czyli naruszenie artykułu 52 Rozporządzenia

Tabela 1. Wyniki urzędowej kontroli jakości środków ochrony roślin w latach 2011-2015

Table 1. Results of official quality control of plant protection products in 2011-2015

\begin{tabular}{|c|c|c|c|c|}
\hline $\begin{array}{l}\text { Rodzaj kontroli } \\
\text { Type of control }\end{array}$ & $\begin{array}{c}\text { Liczba atestów } \\
\text { z orzeczeniem } \\
\text { pozytywnym } \\
\text { Number of certificates } \\
\text { with positive opinion }\end{array}$ & $\begin{array}{c}\text { Liczba atestów } \\
\text { z orzeczeniem } \\
\text { negatywnym } \\
\text { Number of certificates } \\
\text { with negative opinion }\end{array}$ & $\begin{array}{c}\text { Liczba atestów } \\
\text { bez orzeczenia } \\
\text { Number of certificates } \\
\text { without opinion }\end{array}$ & $\begin{array}{l}\text { Całkowita } \\
\text { liczba atestów } \\
\text { Total number } \\
\text { of certificates }\end{array}$ \\
\hline $\mathrm{K}$ & 1284 & 47 & 1 & 1332 \\
\hline $\mathrm{KI}$ & 75 & 165 & 24 & 264 \\
\hline Razem - Total & 1359 & 212 & 25 & 1596 \\
\hline
\end{tabular}

$\mathrm{K}$ - kontrola podstawowa - basic control, $\mathrm{KI}$ - kontrola interwencyjna - interventional control

Tabela 2. Wyniki urzędowej kontroli w latach 2011-2015 dla środków nieobjętych i objętych handlem równoległym Table 2. Results of official control in 2011-2015 for products not covered and covered by parallel trade

\begin{tabular}{|c|c|c|c|c|}
\hline $\begin{array}{l}\text { Rodzaj kontroli } \\
\text { Type of control }\end{array}$ & $\begin{array}{c}\text { Liczba próbek } \\
\text { nieobjętych } \\
\text { handlem równoległym } \\
\text { Number of samples } \\
\text { not from parallel trade }\end{array}$ & $\begin{array}{c}\text { Liczba atestów } \\
\text { z orzeczeniem } \\
\text { negatywnym dla próbek } \\
\text { nieobjętych handlem } \\
\text { równoległym } \\
\text { Number of certificates } \\
\text { with negative opinion for } \\
\text { not parallel trade samples }\end{array}$ & $\begin{array}{c}\text { Liczba próbek } \\
\mathrm{z} \text { handlu równoległego } \\
\text { Number of samples } \\
\text { from parallel trade }\end{array}$ & $\begin{array}{c}\text { Liczba atestów } \\
\text { z orzeczeniem } \\
\text { negatywnym dla próbek } \\
\text { objętych handlem } \\
\text { równoległym } \\
\text { Number of certificates } \\
\text { with negative opinion } \\
\text { for parallel trade samples }\end{array}$ \\
\hline $\mathrm{K}$ & 1082 & 17 & 250 & 30 \\
\hline $\mathrm{KI}$ & 165 & 87 & 99 & 78 \\
\hline Razem - Total & 1247 & 104 & 349 & 108 \\
\hline
\end{tabular}

$\mathrm{K}$ - kontrola podstawowa - basic control, $\mathrm{KI}$ - kontrola interwencyjna - interventional control 
Tabela 3. Wyniki urzędowej kontroli w latach 2011-2015 z uwzględnieniem rodzajów środków ochrony roślin

Table 3. Results of official control in 2011-2015 regarding types of plant protection products

\begin{tabular}{c|c|c|c|c|c}
\hline $\begin{array}{c}\text { Rodzaj kontroli } \\
\text { Type of control }\end{array}$ & $\begin{array}{c}\text { Fungicydy } \\
\text { Fungicides }\end{array}$ & $\begin{array}{c}\text { Herbicydy } \\
\text { Herbicides }\end{array}$ & $\begin{array}{c}\text { Insektycydy } \\
\text { Insecticides }\end{array}$ & $\begin{array}{c}\text { Pozostałe } \\
\text { Others }\end{array}$ & $\begin{array}{c}\text { Razem } \\
\text { Total }\end{array}$ \\
\hline K & 354 & 746 & 160 & 72 & 1332 \\
\hline KI & 80 & 114 & 28 & 42 & 264 \\
\hline Razem - Total & 434 & 860 & 188 & 114 & 1596 \\
\hline
\end{tabular}

$\mathrm{K}$ - kontrola podstawowa - basic control, $\mathrm{KI}$ - kontrola interwencyjna - interventional control

1107/2009. Artykuł ten w punkcie 1. mówi, że ,środek ochrony roślin, który uzyskał zezwolenie w jednym państwie członkowskim (państwie członkowskim pochodzenia), może, $\mathrm{z}$ zastrzeżeniem wydania pozwolenia na handel równoległy, być wprowadzany, wprowadzany do obrotu i stosowany w innym państwie członkowskim (państwie członkowskim wprowadzenia), jeżeli to państwo członkowskie ustali, że skład danego środka ochrony roślin jest identyczny ze składem środka ochrony roślin, który uzyskał już zezwolenie na jego terytorium (środka referencyjnego)". W grupie środków nieobjętych handlem równoległym stosunkowo duży udział w wykrytych nieprawidłowościach miały fałszerstwa oraz nielegalne sprowadzenie na terytorium Polski. Niewielki procent nieprawidłowości stanowiła niewłaściwa zawartość substancji czynnych oraz nieodpowiednie właściwości fizykochemiczne badanych środków. Wyniki badań środków z uwzględnieniem rodzaju zezwolenia na dopuszczenie do obrotu zamieszczono w tabeli 2. Zestawienie zamieszczone w tabeli 3. dotyczące podziału kontrolowanych środków ze względu na ich zastosowanie wskazuje, że największy udział - 53,9\% w całkowitej liczbie kontrolowanych próbek środków stanowiły herbicydy.

\section{Wnioski / Conclusions}

1. Niezależna kontrola jakości ś.o.r. jest elementem systemu ochrony konsumenta i środowiska przed zagrożeniami wynikającymi ze stosowania chemicznej ochrony roślin.

2. Zmiana systemu pobierania próbek w 2012 i 2013 roku umożliwiła rozszerzenie i spowodowała ukierunkowanie kontroli na obszary najbardziej zagrożone nieprawidłowościami.

3. Rezultaty przeprowadzonych badań wykazały, że grupą produktów najbardziej narażoną na występowanie nieprawidłowości są środki objęte handlem równoległym.

4. Stwierdzono generalnie dobrą jakość ś.o.r. w sieciach handlowych oraz wysoką skuteczność kontroli interwencyjnej.

5. Duża różnorodność problemów związanych z kontrolą jakości ś.o.r. powoduje konieczność doskonalenia istniejących oraz opracowywanie nowych metod analitycznych wykorzystywanych przez laboratorium kontrolne oraz potrzebę stałego uzupełniania i pozyskiwania nowego, wysokiej klasy wyposażenia badawczego.

\section{Podziękowanie / Acknowledgements}

Badania sfinansowano ze środków Programu Wieloletniego Instytutu Ochrony Roślin - Państwowego Instytutu Badawczego: „Ochrona roślin uprawnych z uwzględnieniem bezpieczeństwa żywności oraz ograniczenia strat w plonach i zagrożeń dla zdrowia ludzi, zwierząt domowych i środowiska" na lata 2011-2015.

\section{Literatura / References}

MT 3 Specific gravity, density, and weight per millilitre. CIPAC Handbook Volume F. 1995. Physico-chemical Methods for Technical and Formulated Pesticides. Colaborative International Pesticides Analytical Council Ltd.: 11-21.

MT 30.2 Dean and stark method. CIPAC Handbook Volume F. 1995. Analysis of Technical and Formulated Pesticides. Colaborative International Pesticides Analytical Council Ltd.: 93-94.

MT 30.5 Karl Fisher method using pyridine-free reagents. CIPAC Handbook Volume J. 2000. Analysis of Technical and Formulated Pesticides. Colaborative International Pesticides Analytical Council Ltd.: 120-123.

MT 36.3 Emulsion characteristic of emulsifiable concentrates. CIPAC Handbook Volume K. 2003. Analysis of Technical and Formulated Pesticides. Colaborative International Pesticides Analytical Council Ltd.: 137-139.

MT 53 Wettability. CIPAC Handbook Volume F. 1995. Analysis of Technical and Formulated Pesticides. Colaborative International Pesticides Analytical Council Ltd.: 160-166.

MT 75.3 Determination of $\mathrm{pH}$ values. CIPAC Handbook Volume J. 2000. Analysis of Technical and Formulated Pesticides. Colaborative International Pesticides Analytical Council Ltd.: 131-132.

MT 179 Degree of dissolution and solution stability. CIPAC Handbook Volume H. 1998. Analysis of Technical and Formulated Pesticides. Colaborative International Pesticides Analytical Council Ltd.: 307-309.

MT 184 Suspensibility of formulations forming suspensions on dilution with water. CIPAC Handbook Volume K. 2003. Analysis of Technical and Formulated Pesticides. Colaborative International Pesticides Analytical Council Ltd.: 142-148.

MT 185 Wet sieve test. CIPAC Handbook Volume K. 2003. Analysis of Technical and Formulated Pesticides. Colaborative International Pesticides Analytical Council Ltd.: 149-150.

Rozporządzenie 1107/2009. Rozporządzenie Parlamentu Europejskiego i Rady (WE) nr 1107/2009 z dnia 21.10.2009 r. dotyczące wprowadzania do obrotu środków ochrony roślin i uchylające dyrektywy Rady 79/117/EWG i 91/414/EWG. Dz. U. UE nr L 309/1 $\mathrm{z}$ dnia 24.11.2009 r. 